\title{
Article \\ Accurate Measurements of a Wavelength Drift in High-Temperature Silica-Fiber Bragg Gratings
}

\author{
Sergey Dedyulin ${ }^{1, *(\mathbb{D})}$, Elena Timakova ${ }^{1}$, Dan Grobnic ${ }^{2}$, Cyril Hnatovsky $^{2}$, Andrew D. W. Todd ${ }^{1}$ \\ and Stephen J. Mihailov ${ }^{2}$ D \\ 1 Metrology, National Research Council Canada, 1200 Montreal Road, Ottawa, ON K1A 0R6, Canada; \\ etimakova@uvic.ca (E.T.); Andrew.Todd@nrc-cnrc.gc.ca (A.D.W.T.) \\ 2 Security and Disruptive Technologies, National Research Council Canada, 100 Sussex Drive, \\ Ottawa, ON K1A 0R6, Canada; Dan.Grobnic@nrc-cnrc.gc.ca (D.G.); Kyrylo.Hnatovsky@nrc-cnrc.gc.ca (C.H.); \\ Stephen.Mihailov@nrc-cnrc.gc.ca (S.J.M.) \\ * Correspondence: Sergey.Dedyulin@nrc-cnrc.gc.ca
}

Citation: Dedyulin, S.; Timakova, E.; Grobnic, D.; Hnatovsky, C.; Todd, A.D.W.; Mihailov S.J. Accurate Measurements of a Wavelength Drift in High-Temperature Silica-Fiber Bragg Gratings. Metrology 2021, 1, 1-16. https://doi.org/10.3390/ metrology1010001

Academic Editor: Gianluca Galzerano

Received: 6 March 2021

Accepted: 1 April 2021

Published: 14 April 2021

Publisher's Note: MDPI stays neutral with regard to jurisdictional claims in published maps and institutional affiliations.

Copyright: (c) 2021 by the authors. Licensee MDPI, Basel, Switzerland. This article is an open access article distributed under the terms and conditions of the Creative Commons Attribution (CC BY) license (https:/ / creativecommons.org/licenses/by/ $4.0 /)$.

\begin{abstract}
Fiber Bragg gratings (FBG) are extensively used to perform high-temperature measurements in harsh environments, however the drift of the characteristic Bragg wavelength affects their long-term stability resulting in an erroneous temperature measurement. Herein we report the most precise and accurate measurements of wavelength drifts available up to date on high-temperature FBGs. The measurements were performed with a set of packaged $\pi$-phase-shifted FBGs for high wavelength resolution, in caesium and sodium pressure-controlled heat pipes for stable temperature environment and with a tunable laser for stable wavelength measurements with a $0.1 \mathrm{pm}$ resolution. Using this dataset we outline the experimental caveats that can lead to inconsistent results and confusion in measuring wavelength drifts, namely: influence of packaging; interchangeability of FBGs produced under identical conditions; birefringence of $\pi$-phase-shifted FBGs; initial transient behaviour of FBGs at constant temperature and dependence on the previous thermal history of FBGs. In addition, we observe that the wavelength stability of $\pi$-phase-shifted gratings at lower temperature is significantly improved upon by annealing at higher temperature. The lowest value of the wavelength drift we obtain is $+0.014 \mathrm{pm} \cdot \mathrm{h}^{-1}$ at $600{ }^{\circ} \mathrm{C}$ (corresponding to $+0.001{ }^{\circ} \mathrm{C} \cdot \mathrm{h}^{-1}$ ) after annealing for $400 \mathrm{~h}$ at $1000^{\circ} \mathrm{C}$, the longest annealing time we have tried. The annealing time required to achieve the small drift rate is FBG-specific.
\end{abstract}

Keywords: fiber Bragg grating; wavelength drift; pressure-controlled heat pipe

\section{Introduction}

Traditionally, the majority of high-temperature measurements for applications in the $600{ }^{\circ} \mathrm{C}-1200{ }^{\circ} \mathrm{C}$ temperature range were done with various thermocouples that measure the electromotive force between two dissimilar metal wires wherever a temperature gradient is present along the entire length of the thermocouple [1] (pp. 239-281). Three main disadvantages of thermocouples that currently limit their use are their large size (the electromotive force is essentially generated by thermal gradients along the entire length of the thermocouple), redistribution of impurities/dopants along the thermocouple length at high temperatures (the electromotive force is thus altered during the measurements) and sensitivity to electromagnetic interference and ionizing radiation [1] (pp. 239-281), [2].

Recently, fiber optic sensors were used instead to perform high-temperature measurements in a large number of sensing applications in harsh environments-such as structural fire testing [3,4], metal casting [5], nuclear power plants [6,7], tokamak [8], combustion and gas turbine engines $[9,10]$. The majority of the reported studies involved Bragg gratings inscribed in doped silica fiber with high-intensity infrared femtosecond lasers or ultraviolet lasers by means of a direct writing or writing through a phase mask, which creates periodic variations of the refractive index in the fiber core $[11,12]$. These periodic variations 
with a period $\Lambda$ produce a condition for interference of light propagating in the fiber: $2 \cdot n_{e f f} \cdot \Lambda=\lambda_{B}$, where $\lambda_{B}$ is known as the Bragg wavelength and $n_{e f f}$ is the effective refractive index of the fiber core at $\lambda_{B}$. As both $n_{\text {eff }}$ and $\Lambda$ are functions of temperature, $\lambda_{B}$ is also correlated with the temperature.

Fiber Bragg gratings (FBGs) are, at a first glance, ideally suited to high-temperature measurements in harsh environments due to being small, insensitive to electromagnetic radiation, resistant to corrosive environments, capable of multiplexing and relatively cheap to manufacture. However, the first experiments involving FBGs in high-temperature environments had three major drawbacks: they lacked a systematic approach; they were primarily concerned with survivability of the FBG sensors on a short time scale; and they were typically performed in a tube furnace or in a specific application setting (e.g., simulated nuclear reactor environment) with a relatively low wavelength and temperature resolution and a relatively poor temperature stability and homogeneity. Closer examination [13] revealed ubiquitous wavelength drifts present across different grating types at high-temperatures which directly impacts applications involving high-accuracy and high-precision temperature measurements (e.g., temperature metrology) and applications that require long-term temperature monitoring, sometimes at the level of years (e.g., in nuclear reactors). The underlying mechanism for the wavelength drifts so far remains disputed. Three effects that are commonly invoked in the literature to explain the wavelength drifts [13] are dopant diffusion from the core, devitrification (crystallization) of the glass, and release of stresses that are built into the fiber during the fiber manufacturing process. It is likely that not a single cause, but a combination of several factors, are responsible for the observed wavelength drifts.

In an attempt to shed light on the origin of the wavelength drift and eliminate some of the aforementioned drawbacks present in the previous research, we embarked on a systematic study of the long-term drifts in packaged $\pi$-phase-shifted femtosecond laser written gratings that promise an improved wavelength stability [14].

Our experimental set-up described in Section 2, is ideally suited for this study by offering long-term temperature stability and high wavelength resolution and stability. We then proceed to describe the experimental caveats that could lead to inconsistent results and confusion in measuring wavelength drifts using our high-accuracy and highprecision dataset, namely: influence of packaging (Section 3.1); interchangeability of FBGs produced under identical conditions (Section 3.2); initial transient behaviour of FBGs at constant temperature (Section 3.3); birefringence of $\pi$-phase-shifted FBGs (Section 3.4) and dependence on the previous thermal history of FBGs (Section 3.5). The lessons learned from this work are followed in Section 3.6 by our confirmation of the previous observation that the wavelength stability of $\pi$-phase-shifted gratings at lower temperature is significantly improved upon annealing at higher temperature. We conclude in Section 4 by summarizing the factors to consider when one is measuring the long-term stability of FGBs and by drawing some parallels with the well-established platinum resistance thermometers (PRTs) in the temperature metrology field.

\section{Materials and Methods}

For the long-term stability measurements, several identical $\pi$-phase-shifted Type II FBGs [15] were fabricated in acrylate-coated SMF-28 single mode fiber using a third order phase mask and Fourier-transform-limited $80 \mathrm{fs}$ pulses from a regeneratively amplified Ti:sapphire laser operating at $\lambda=800 \mathrm{~nm}$ with $1 \mathrm{~mJ}$ pulse energy as described in detail in [14]. It is well known that FBGs at a high constant temperature experience a Bragg wavelength shift which can range from a few picometers to hundreds of picometers depending on the annealing time [14]. We chose $\pi$-phase-shifted Type II FBGs for our experiments in order to allow measurements of spectral shifts with a picometer precision, since these gratings have a very narrow pass-band feature in the center of their resonance spectra (see Figure 1). 


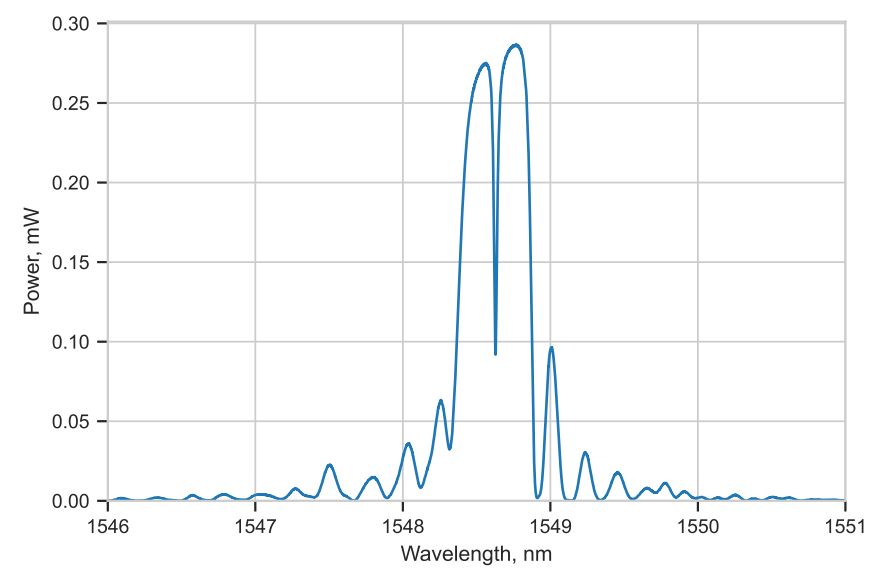

Figure 1. An example of a $\pi$-phase-shifted spectrum for probe 27 at room temperature.

After the inscription, all the FBGs were packaged in a protective 6.5-mm OD quartz tubing by a commercial sensor company (FIBOS [16]). The tubing was flame-sealed at the sensor end. At the opposite (cold) end, a few different sealing options were explored: all of them involving a combination of commercial off-the-shelf Swage-type connectors and a high-temperature epoxy rated to $200{ }^{\circ} \mathrm{C}$ which was used to affix the fiber to the connector. All the FBGs were hanging freely inside the protective tubing with the grating element located at the very tip. The protective acrylic coating on the fibers was left to burn off during the high-temperature annealing. No attempt was made to control the gas atmosphere inside the protective tubing. Throughout the testing process, a few packaged FBGs failed upon the high-temperature annealing (see Section 3.1), so in Table 1 we list only the test results for three survivors that, expectedly, had identical packaging. For each measurement the following information is shown: the date of the measurement; probe serial number; annealing time at $1000^{\circ} \mathrm{C}$ prior to the measurement; where the measurement took place (i.e., in caesium (Cs) or sodium (Na) pressure-controlled heat pipe (PCHP) or in the triple-point-of-water (TPW) cell); nominal measurement temperature, $\mathrm{T}_{\text {nom }}$, and duration of the measurement, Time $@ \mathrm{~T}_{\text {nom; }}$ measured drift rate, rounded to 3 decimal figures for consistency; the wavelength at the start and at the end of the measurement. Unsuccessful round-robin (RR) measurement is also shown to complete the picture.

All the FBGs were interrogated in reflection mode using an Agilent 8164 Lightwave Measurement System (Agilent Technologies, Santa Clara, CA, USA) with an integrated tunable laser $(0.1 \mathrm{pm}$ wavelength resolution) and detector modules. We tested the longterm stability of the laser wavelength calibration using a fiber-coupled acetylene gas reference cell [17] (Wavelength References, $5.5 \mathrm{~cm}$ long, 740 Torr) and found no wavelength change (within the resolution of the laser) for the selected absorption line (P25, $1540.82744(11) \mathrm{nm}$ [18]) over the course of $94 \mathrm{~h}$. At each temperature the resonance scans were recorded multiple times (every 5 to $10 \mathrm{~min}$ ) and the selected resonance wavelength was determined by fitting a $20 \mathrm{pm}$ region around the resonance (i.e., a small fraction of the full peak) to a Gaussian function.

In our temperature experiments we used sodium- $(\mathrm{Na})$ and caesium-filled $(\mathrm{Cs})$ pressurecontrolled heat pipe (PCHP) furnaces known for their superior temperature uniformity and stability compared to a tube furnace $[19,20]$. The heat pipe is a heat transfer device in which a small quantity of a working fluid (e.g., caesium) constantly cycles between the evaporator with its external heater(s) and the condenser with its external cooling system/cooler (Figure 2). The liquid is returned to the boiling area by a capillary action through a wick structure along the inner surface of the heat pipe. In the isothermal region between the evaporator and the condenser, the vapour-liquid equilibrium is realized as determined by the pressure-temperature curve for a given working fluid. In the PCHP, the temperature of the isothermal region is precisely controlled by external gas pressure (typically helium). By changing the pressure set point of external gas (helium) we were 
able to realize annealing temperatures between $370{ }^{\circ} \mathrm{C}$ and $660{ }^{\circ} \mathrm{C}$ for the Cs-PCHP and between $600{ }^{\circ} \mathrm{C}$ and $960{ }^{\circ} \mathrm{C}$ for the Na-PCHP. The temperature of the isothermal region was then maintained to within $\pm 0.01{ }^{\circ} \mathrm{C}$ for hours at a time as evidenced by a PRT placed in the neighbouring thermal well.

Table 1. Summary of testing of $\pi$-phase-shifted high-temperature gratings conducted in Cs- and Na-PCHP at NRC.

\begin{tabular}{cccccccc}
\hline $\begin{array}{c}\text { Date } \\
\text { (yy/mm/dd) }\end{array}$ & Probe № & $\begin{array}{c}\text { Time } \\
\mathbf{1 0 0 0}{ }^{\circ} \mathbf{C}\end{array}$ & PCHP & $\mathbf{T}_{\text {nom }}\left({ }^{\circ} \mathbf{C}\right)$ & $\begin{array}{c}\text { Time@ } \\
\mathbf{T}_{\text {nom }} \mathbf{( h )}\end{array}$ & $\begin{array}{c}\text { Drift Rate } \\
\left(\mathbf{p m} \cdot \mathbf{h}^{-1} \mathbf{)}\right.\end{array}$ & $\begin{array}{c}\text { Start-End } \\
\text { Wavelength (nm) }\end{array}$ \\
\hline $19 / 10 / 21$ & 27 & 22 & TPW & 0.01 & 50 & -0.002 & $1548.303-1548.304$ \\
$19 / 10 / 23$ & 27 & 22 & $\mathrm{Cs}$ & 400 & 29 & +0.021 & $1553.258-1553.258$ \\
$19 / 10 / 25$ & 27 & 22 & $\mathrm{Cs}$ & 600 & 14 & +0.195 & $1556.298-1556.300$ \\
$19 / 10 / 28$ & 27 & 22 & $\mathrm{Cs}$ & 600 & 55 & +0.106 & $1556.301-1556.307$ \\
$19 / 10 / 31$ & 27 & 22 & $\mathrm{Cs}$ & 400 & 25 & +0.019 & $1553.267-1553.268$ \\
$19 / 11 / 13$ & 27 & 22 & $\mathrm{Na}$ & 800 & 38 & +0.460 & $1559.540-1559.565$ \\
$19 / 11 / 25$ & 27 & 22 & $\mathrm{Cs}$ & 600 & 18 & +0.098 & $1556.332-1556.334$ \\
$19 / 12 / 02$ & 27 & 22 & $\mathrm{Na}$ & 930 & 6 & -0.946 & $1562.048-1562.121$ \\
$19 / 12 / 09$ & 27 & 22 & $\mathrm{Cs}$ & 600 & 16 & +0.107 & $1556.339-1556.342$ \\
$20 / 01 / 13$ & 27 & 123 & $\mathrm{Cs}$ & 600 & 24 & +0.066 & $1556.403-1556.405$ \\
$20 / 03 / 12$ & 27 & 123 & $\mathrm{Na}$ & 600 & 30 & +0.075 & $1556.413-1556.415$ \\
\hline $19 / 11 / 26$ & 23 & 0 & $\mathrm{Cs}$ & 600 & 18 & +0.031 & $1556.215-1556.216$ \\
$19 / 12 / 10$ & 23 & 98 & $\mathrm{Cs}$ & 600 & 7 & +0.199 & $1556.500-1556.501$ \\
$20 / 01 / 15$ & 23 & 199 & $\mathrm{Cs}$ & 600 & 6 & +0.023 & $1556.549-1556.549$ \\
$20 / 03 / 11$ & 23 & 300 & $\mathrm{Na}$ & 600 & 6 & +0.038 & $1556.544-1556.544$ \\
\hline $19 / 11 / 27$ & 28 & 100 & $\mathrm{Cs}$ & 600 & 22 & +0.229 & $1556.504-1556.508$ \\
$19 / 12 / 10$ & 28 & 198 & $\mathrm{Cs}$ & 600 & 16 & +0.143 & $1556.553-1556.555$ \\
$20 / 01 / 14$ & 28 & 299 & $\mathrm{Cs}$ & 600 & 15 & +0.052 & $1556.558-1556.559$ \\
$20 / 03 / 11$ & 28 & 400 & $\mathrm{Na}$ & 600 & 11 & +0.014 & $1556.541-1556.541$ \\
\hline $19 / 11 / 18$ & $\mathrm{RR}: 22,23,25,27$ & $\mathrm{Cs}$ & 600 & 72 & $\mathrm{n} / \mathrm{a}$ & $\mathrm{n} / \mathrm{a}$ \\
\hline
\end{tabular}

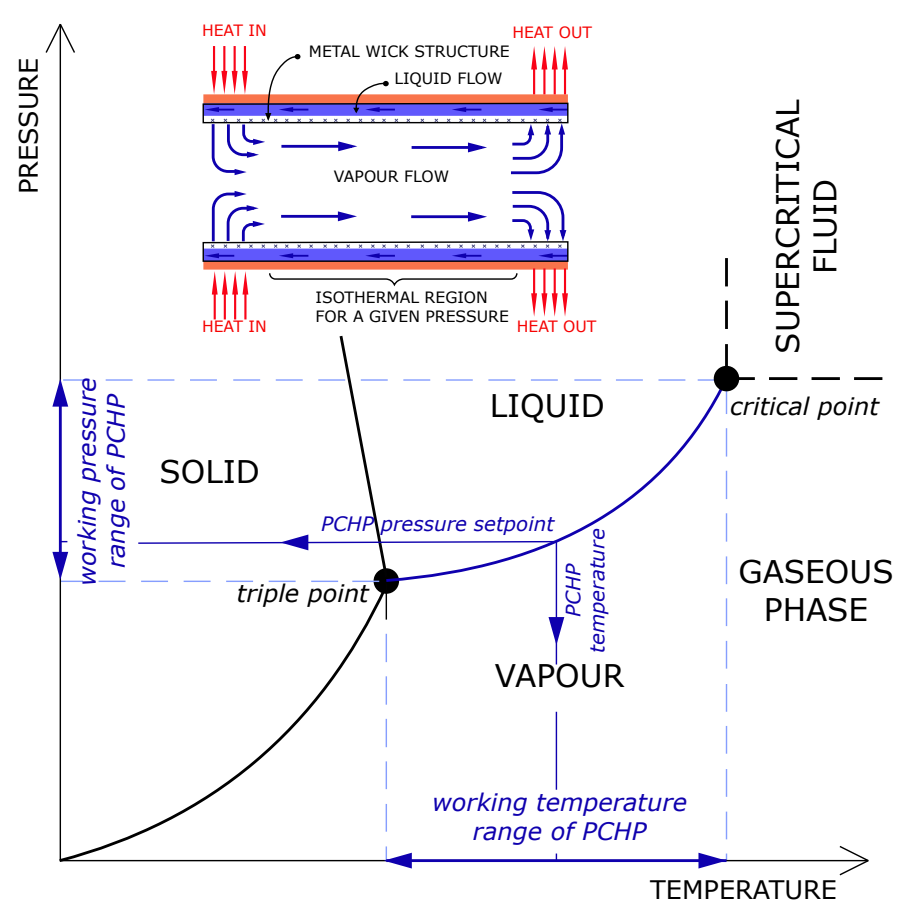

Figure 2. A phase diagram of a one-component system as applied to a PCHP. A schematic of a working PCHP is shown in the inset. 
In Figure 3, we schematically show the summary of the experiments performed in this work and presented in Table 1. Our primary goal, when setting up the experiments, was to check how much the stability at lower temperatures could be improved upon higher-temperature annealing as depicted by the top-left rectangle in Figure 3. In our previous work [14], we observed that the $\pi$-features of all the FBGs tested at $1000{ }^{\circ} \mathrm{C}$ shifted towards longer wavelength by $150-250 \mathrm{pm}$ only during the first $30-50$ cumulative hours of annealing at $1000{ }^{\circ} \mathrm{C}$ and almost no shift could be detected during the later stages of the experiment. The lower temperature for testing the improved performance had to be "high" enough that the wavelength drift could be detected in reasonable time and "low" enough that we could use Cs-PCHP. Thus, for the base-line measurements we chose $600{ }^{\circ} \mathrm{C}$ because we could easily detect a typical $+0.1 \mathrm{pm} \cdot \mathrm{h}^{-1}$ drift rate over the course of a single day and because running at temperatures above $600{ }^{\circ} \mathrm{C}$ would require use of the Na-PCHP and we currently do not have a back-up in case of the Na-PCHP failure. In parallel, we also investigated, to a limited extent, the drift rate as a function of PCHP temperature and the effects of birefringence and packaging on sensor's performance as depicted by top-middle and top-right rectangles in Figure 3. In all the experiments, we always checked the drift rate at $600{ }^{\circ} \mathrm{C}$ before and after the experiment for any changes in the drift rate.

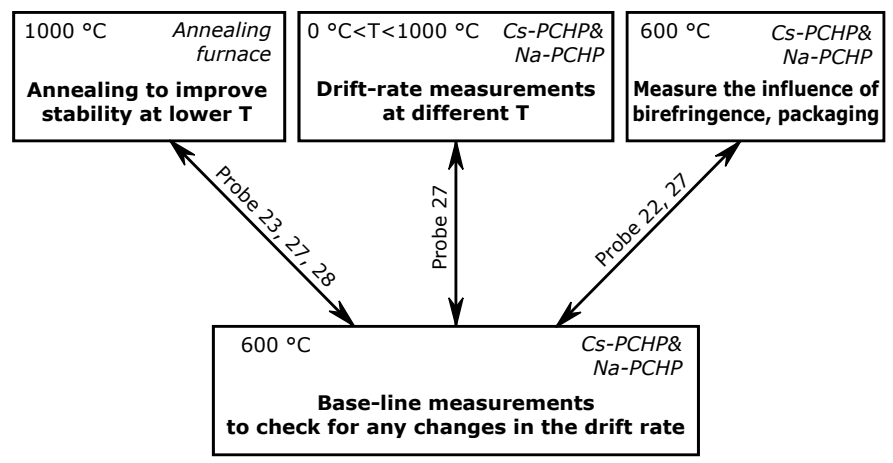

Figure 3. A schematic representation of the experiments performed in this work.

\section{Results}

\subsection{Before You Start: The Importance of Packaging}

When studying the wavelength drifts in a batch of (high-temperature) FBGs, one typically spends a great deal of time ensuring that the FBGs are produced under identical conditions to enable a fair comparison. Consequently, more information is provided in the published literature about the FBG's production method than about the packaging used for testing the wavelength drift in the furnace. The following three details of the packaging are typically omitted: the strain-free mounting of the fibers inside the protective sheath, the sealing of the gas atmosphere inside the sheath and the means to ensure the thermal contact with the environment. Lack of attention to the packaging of FBG sensors could be contrasted with the well-established high-temperature PRTs where the packaging and related issues, such as the material for the protective sheath, gas atmosphere inside the sheath, design of the strain-free mount for the sensor element, were recognized during early development and are covered at great length [1] (pp. 153-198), [21].

In our own studies we found that inappropriate packaging could lead to excessive wavelength drifts at high temperatures and eventually to probe failure. For example, in Figure 4 we show how probe 22 upon its first exposure to $600{ }^{\circ} \mathrm{C}$ manifested a drift rate that was more than 10 times higher than that of the probes 23, 27 and 28 (Table 1). Produced under identical conditions, it developed a black deposit along the surface of the quartz sheath and eventually failed-no grating peak could be detected in the spectrum. The only difference between probe 22 and probes 23,27 and 28 was in a small detail of the packaging-a Swage-type connector was epoxied directly to the quartz tube's end, which was likely getting too hot during the experiments in the heat-pipe furnace through heat conduction. We speculate that the heating of the epoxy above the rated temperature limit 
resulted in its degradation and re-deposition of by-products everywhere inside the sheath including the FBG portion of the fiber. It is yet unclear how this re-deposition led to the subsequent FBG failure and further experimentation with the packaging is necessary.

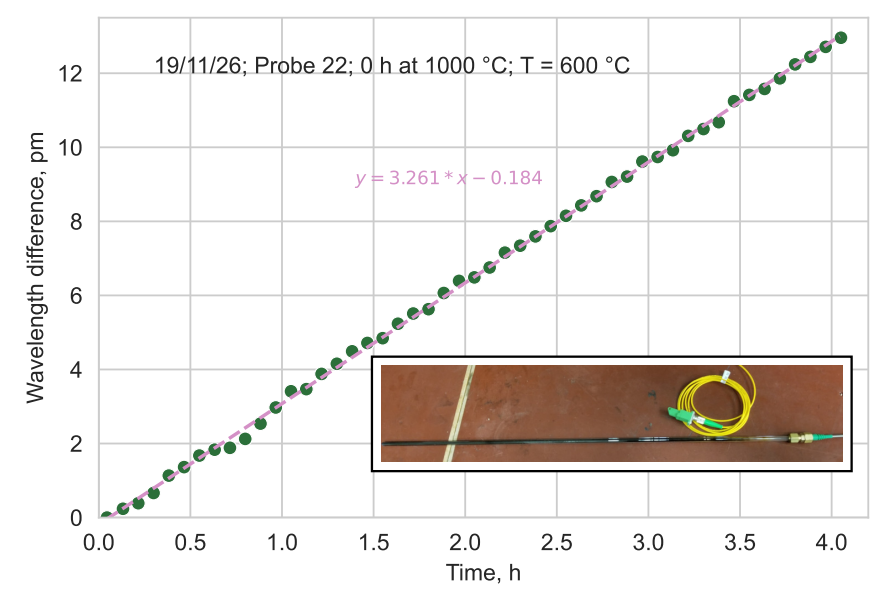

Figure 4. Probe 22 showed excessive drift (compared to probes 23,27 and 28 packaged differently) when it was first measured at $600{ }^{\circ} \mathrm{C}$ (no pre-annealing at $1000{ }^{\circ} \mathrm{C}$ ). It developed a black deposit inside the protective quartz tubing and eventually failed.

On the other hand, our recent results [13] indicate that, once the details of the packaging are rectified, the same trends are observed with packaged and unpackaged FBGs, which shows that a properly designed package minimally affects the long-term behaviour of the FBG temperature sensors inside it.

In our future work we are also planning to investigate the influence of the gas composition inside the sealed probe on the FBG long-term stability. For example, in [22] it was shown that the cladding of the single mode fiber could contain a significant amount of water. Changes in the amount and distribution of water in the cladding upon hightemperature annealing could lead to changes in the Bragg wavelength due to changes in the effective refractive index similarly to what happens at room temperature $[23,24]$. Oxidation at high temperatures from the partial oxygen pressure inside the sheath or degradation of the fiber/grating due to decomposition of water molecules at high temperature could also be an issue.

\subsection{Planning the Experiment: How Identical Are the Gratings}

Continuing with the issues that are typically overlooked in the experiments with hightemperature FBGs, the inevitable variability of the FBG sensors comes up, even though the gratings are produced with a great care under as much identical conditions as possible. In Figure 5, we show our own results from [13] obtained with unpackaged $\pi$-phase-shifted Type II FBGs at $1000{ }^{\circ} \mathrm{C}$ produced under identical laser-writing conditions. The same conditions were also used to fabricate the packaged fibers that are described earlier. Notice how the gratings 1 and 5, produced under identical conditions from the same batch of fiber, identically treated and measured in the same furnace under identical conditions, nevertheless manifest an opposite drift behaviour. Moreover, gratings 4 and 5, despite following the same pattern for the wavelength drift, exhibit wavelength drift rates different by more than a factor of 3 (when the last $200 \mathrm{~h}$ are considered). 


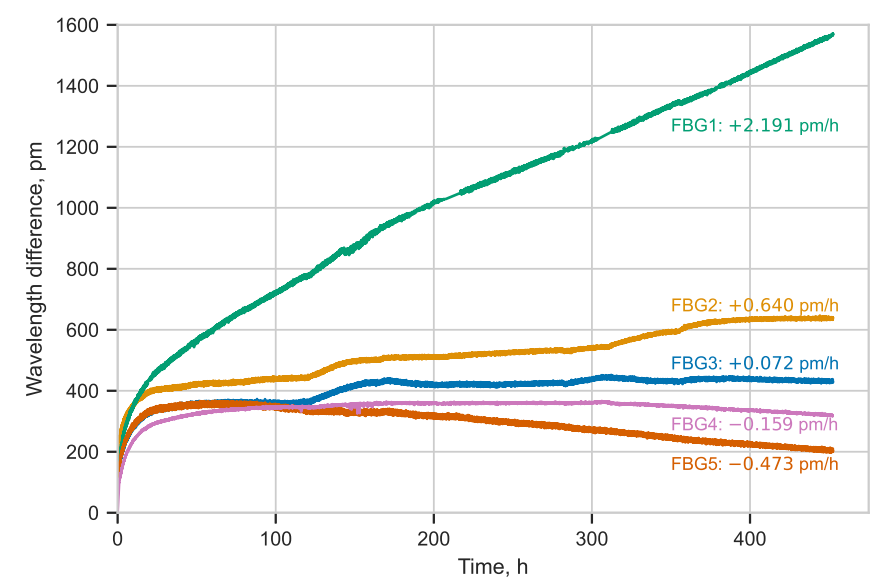

Figure 5. Five unpackaged $\pi$-phase-shifted Type II FBGs at $1000{ }^{\circ} \mathrm{C}$, produced and treated identically, yet exhibit different drift behaviour in terms of both magnitude and sign [13].

The main implication of this unique nature of individual FBG gratings-likely resulting from the sensitivity of the inscription process to minute differences in positioning of the fiber with respect to the laser focus and small structural and stress variations in the fiber itself-is that each and every grating should be calibrated individually for the temperature range of interest prior to performing temperature measurements. It no longer suffices to specify that the gratings were produced under identical conditions, so that the differences obtained with $N$ "identical" gratings at $M$ temperatures are indicative of the temperature differences between them. Strictly speaking, this conclusion applies only to $\pi$-phase-shifted Type II FBGs made with a phase mask method and other methods may have a higher repeatability rate. However, the important point is that all temperature sensors should be checked first for how identical they are. A few individual sensors could be checked/calibrated together by placing them at the same point in the furnace-a common practice in the temperature calibration labs.

\subsection{Planning the Experiment: How Long is Long-Term}

Another important consideration for planning the experiment is its duration: for how long should one maintain the stable temperature environment in order to measure a repeatable and consistent drift rate. For example, in Figure 6 we show how important it is to wait for $5-10 \mathrm{~h}$ in order that the drift rate stabilizes. In this case, probe 27 was maintained at the nominal temperature of $600{ }^{\circ} \mathrm{C}$ in a Cs-PCHP for over 2 days within $0.005{ }^{\circ} \mathrm{C}$ (equivalent to a $0.075 \mathrm{pm}$ wavelength shift) while the position of the $\pi$-phaseshifted feature was constantly monitored with a $0.1 \mathrm{pm}$ resolution. Despite the temperature of the Cs-PCHP being stable within the resolution of the FBG thermometer, the wavelength experienced an initial drop in the first several hours of the experiment which resulted in an apparent negative drift rate of $-0.056 \mathrm{pm} \cdot \mathrm{h}^{-1}$ over the course of the first $6 \mathrm{~h}$ instead of $+0.114 \mathrm{pm} \cdot \mathrm{h}^{-1}$ measured after $50 \mathrm{~h}$ at $600^{\circ} \mathrm{C}$. The latter number-obtained for the portion of the curve when the drift rate had stabilized-is more consistent with the previous observations reported in Table 1 and was retained. 


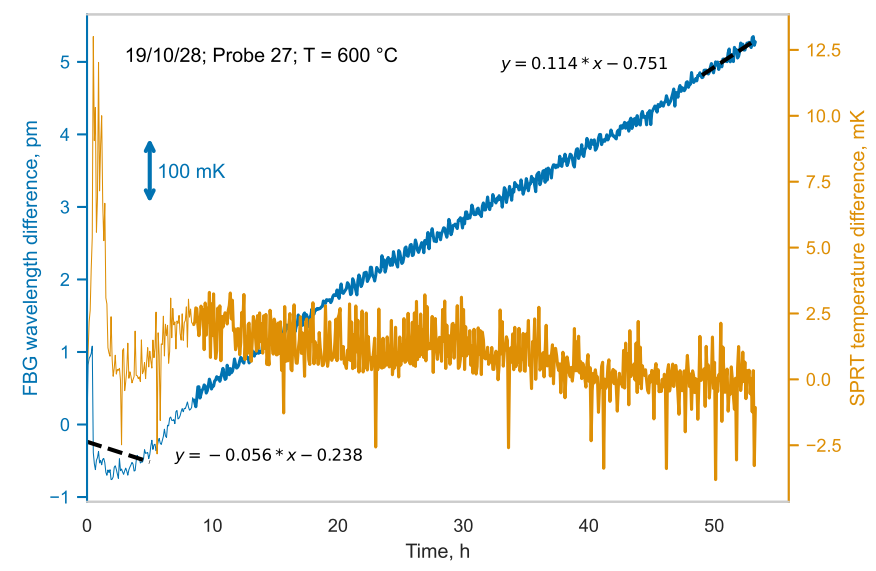

Figure 6. Probe 27 measured on $19 / 10 / 28$ in a Cs-PCHP at $600{ }^{\circ} \mathrm{C}$. Shown in bold is the region used for finding the drift rate of $+0.106 \mathrm{pm} \cdot \mathrm{h}^{-1}$ reported in Table 1 . Failure to wait for sufficient time at constant temperature could result in a different value for the drift rate: linear fits for the first $6 \mathrm{~h}$ $\left(\right.$ drift rate of $\left.-0.056 \mathrm{pm} \cdot \mathrm{h}^{-1}\right)$ and the last $6 \mathrm{~h}\left(\right.$ drift rate of $+0.114 \mathrm{pm} \cdot \mathrm{h}^{-1}$ ) are shown.

The choice of a six-hour window to calculate the FBG drift rate in the example above was not accidental: it is equal to the shortest duration of the experiments that we occasionally performed in the Cs-PCHP and Na-PCHP due to technical limitations and could potentially explain some of the observed anomalies in the reported drift rate numbers as illustrated further below. In Figure 7, we show a series of experiments of measuring the drift rate in the triple-point-of-water cell $\left(0.01{ }^{\circ} \mathrm{C}\right)$, in the $\mathrm{Cs}-\mathrm{PCHP}\left(400{ }^{\circ} \mathrm{C}\right.$ and $\left.600{ }^{\circ} \mathrm{C}\right)$ and Na-PCHP $\left(800^{\circ} \mathrm{C}\right.$ and $\left.930^{\circ} \mathrm{C}\right)$ for probe 27 . Note that we did not monitor the wavelength during the annealing at $1000{ }^{\circ} \mathrm{C}$. Hence, the drift rate at $1000{ }^{\circ} \mathrm{C}$ was calculated by comparing the final wavelength of the $\pi$-feature at $600{ }^{\circ} \mathrm{C}$ before the annealing and the initial wavelength of the $\pi$-feature at $600{ }^{\circ} \mathrm{C}$ after the annealing. The drift rate is very small below $500{ }^{\circ} \mathrm{C}$ and starts becoming noticeable at $600{ }^{\circ} \mathrm{C}$, with its ever-increasing trend suddenly being reversed during the $6 \mathrm{~h}$ at $930^{\circ} \mathrm{C}$. The short time duration in this case was chosen because it takes a longer time for the Na-PCHP to reach a stable high-temperature set-point and because we were unable to leave this experiment unattended overnight due to safety concerns $\left(930^{\circ} \mathrm{C}\right.$ is very close to the operating limit for the Na-PCHP. The life time of the PCHP decreases when operated at higher temperatures and the probability of failure increases). As a result, it is entirely possible that the measured negative drift rate of $-0.946 \mathrm{pm} \cdot \mathrm{h}^{-1}$ is due to insufficient time for it to stabilize. The positive drift rate at $100{ }^{\circ} \mathrm{C}$, albeit measured post factum, further corroborates this conclusion. In our future work, long term test will be performed to validate this hypothesis. 


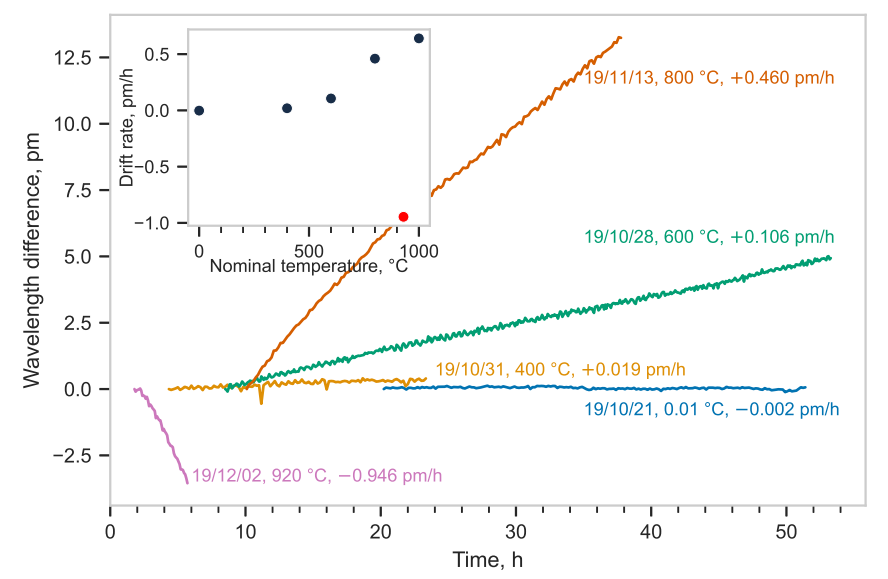

Figure 7. Stability of probe 27 (annealed for $22 \mathrm{~h}$ at $1000^{\circ} \mathrm{C}$ ) as a function of temperature. Inset: drift rate as a function of temperature $\left(1000{ }^{\circ} \mathrm{C}\right.$ data point is calculated by comparing the resonance wavelength before and after annealing). The stability of the probe is quickly deteriorating past the $400{ }^{\circ} \mathrm{C}$ mark. The "outlier" $920{ }^{\circ} \mathrm{C}$ measurement is likely due to insufficient waiting time at that temperature.

\subsection{Planning the Experiment: Birefringence}

Another issue specific to $\pi$-phase-shifted gratings that one has to keep in mind while planning the experiments is their reported birefringence [25]. For a regular single-mode fiber, this means that the light generally propagates in a superposition of two orthogonal polarizations which are strongly coupled to each other meaning that the energy from one polarization state could be transferred to the orthogonal state and vice versa. Each polarization state has a slightly different resonant wavelength [25] and relative weight in the linear combination that is typically measured in an experiment without polarization control. The relative weights and, as a consequence, the measured wavelength of the linear combination of the two orthogonal polarizations will change if there are any changes in the ambient temperature (outside of the furnace) or stress applied to the fiber (for example a pressure or a bend introduced in a new point) which will contribute to the scatter in the measured wavelength.

We encountered the birefringence-related issue when we attempted to run a roundrobin measurement of four FBGs in the Cs-PCHP while using a single laser/detector system and manually connecting/disconnecting the four FBGs to it at regular time intervals. The FBG probes had a total fiber length of approximately $1 \mathrm{~m}$ terminated at one end with a E-2000 female connector. We discovered that the wavelength scatter introduced by each connection/disconnection procedure of approximately $2 \mathrm{pm}$ on average (and up to $350 \mathrm{pm}$ in one outlier) completely obscured the wavelength drift for each FBG. Thereafter we switched to continuously monitoring the wavelength over a prolonged period of time for each FBG individually.

In order to verify that the two polarization components indeed show the same drift rate as their linear combination does, we installed a polariser in front of the detector. We then switched the polarization state back and forth between the two orthogonal directions without disturbing anything else in the system while measuring the wavelength drift in probe 27 at $600{ }^{\circ} \mathrm{C}$ for a full day as shown in Figure 8. Then, the polariser was carefully removed from the system and the wavelength drift with no polariser was also recorded. In all three instances we measured the same (within experimental uncertainties) linear slope for the wavelength as a function of time. This observation is important because if we assume that the wavelength drift is caused by stress relaxation in the fiber, the slopes should be different as the stress-related components of the FBG response are expected to have different temperature dependencies. 


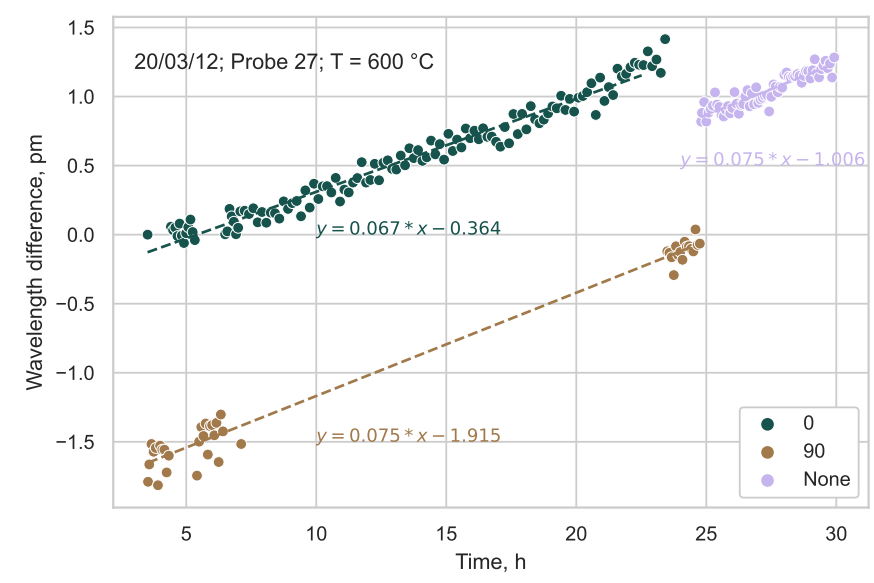

Figure 8. Wavelength drift in probe 27 as a function of time when a polariser is installed in front of the detector. The same (within experimental uncertainties) linear slope for the wavelength as a function of time suggests that the origin of the wavelength drift is not due to changing stress in the fiber.

\subsection{Measurement Results: The Additivity of Wavelength Drifts}

Careful examination of the results reported in Table 1 for probe 27 leads to an interesting, albeit simple, observation: the wavelength drifts at temperatures below $930{ }^{\circ} \mathrm{C}$ are additive by nature. In other words, if, after the measurements are completed at the temperature $T_{1}$ with the final measured wavelength $\lambda_{f}\left(T_{1}^{\text {old }}\right)$, the probe undergoes a subsequent annealing at temperature $T_{2}$ for some time $\Delta t_{2}$ and the measurement at $T_{1}$ is repeated, then the initial wavelength for this repeated measurement, $\lambda_{i}\left(T_{1}\right)$ will be given by:

$$
\lambda_{i}\left(T_{1}^{\text {new }}\right)=\lambda_{f}\left(T_{1}^{\text {old }}\right)+\Delta \lambda\left(T_{2}\right) \approx \lambda_{f}\left(T_{1}^{\text {old }}\right)+r_{\lambda}\left(T_{2}\right) \times \Delta t_{2}
$$

where $\Delta \lambda\left(T_{2}\right)$ is the total wavelength change upon exposure to the temperature $T_{2}$ and $r_{\lambda}\left(T_{2}\right)$ is the wavelength drift rate at temperature $T_{2}$. As an illustration, consider two measurements of probe 27 at $600{ }^{\circ} \mathrm{C}$ on 25 October 2019 and on 25 November 2019, separated by a month: in between we completed a measurement at $600{ }^{\circ} \mathrm{C}$ for $55 \mathrm{~h}$, at $400{ }^{\circ} \mathrm{C}$ for $25 \mathrm{~h}$, at $800{ }^{\circ} \mathrm{C}$ for $38 \mathrm{~h}$ and an unsuccessful round-robin at $600{ }^{\circ} \mathrm{C}$ for $72 \mathrm{~h}$ (since the drift rate in the round-robin experiment could not be measured, we use the drift rate at $600{ }^{\circ} \mathrm{C}$ as determined on the successive date, $19 / 11 / 25$, for the calculations). Using the additivity principle described above, the initial wavelength for the measurement on 25 November 2019 should be: $\lambda_{i}\left(T_{600}^{19 / 11 / 25}\right) \approx 1556.300+0.001 \times(55 \times 0.106+25 \times$ $0.019+38 \times 0.460+72 \times 0.098)=1556.331 \mathrm{~nm}$-in excellent agreement with the actually measured value of $1556.332 \mathrm{~nm}$. Note that the measurement at $930{ }^{\circ} \mathrm{C}$ is an outlier, as discussed in Section 3.3, and an exception from this additivity rule. We are planning to repeat the measurement at $930{ }^{\circ} \mathrm{C}$ for a longer period of time.

These results could indicate either a permanent reduction of stress due to changes in the internal structure of the glass fiber itself or due to permanent changes in the distribution of the dopant/impurities. Both of these effects will be additive as the sample is submitted to different temperatures. The temperatures examined in this work are too low to lead to the devitrification of the glass - the third cause which is believed to be responsible for the wavelength drifts as we described in Section 1. Interestingly, the additivity of wavelength changes described above could be used to mitigate the wavelength drifts and avoid frequent calibrations, similar to the way it is done with high-temperature PRTs [1] (pp. 153-198), [21]. In the latter case, rather than calibrating a PRT in terms of resistance at various high-temperature points, a ratio of resistance at any given temperature to the ratio at the TPW $\left(0.01^{\circ} \mathrm{C}\right)$ is used instead. Since most of the resistance changes that happened at high temperature are also present at the TPW, the resistance ratio allows one to mitigate the drifts in a PRT to a large extent. 


\subsection{Measurement Results: Improved Stability after Annealing at Higher Temperature}

As described in Section 2, in our previous work [14], we saw that the general ineptitude of the optical fibers for very accurate high-temperature measurements could be potentially improved if the fiber is pre-annealed at a temperature that exceeds the highest test temperature. This observation is likely related to a well known phenomenon in the glass industry: stabilization of the glass viscosity (and related properties) when the glass is annealed at the strain point temperature (or above) for a prolonged period of time [26]. Alternatively, thermal expansion of the glass fiber at $1000^{\circ} \mathrm{C}$ and the resultant irreversible changes to the grating length at a lower temperature could also be the cause, similarly to what was previously observed for bulk glass samples [27]. We were thus interested to quantify the improved stability using our very stable and high-resolution set-up described in Section 2.

First of all, similar to [14], we observed a general reduction in the wavelength drift at $1000{ }^{\circ} \mathrm{C}$ as the total time spent at $1000{ }^{\circ} \mathrm{C}$ increases. In Figure 9, we plotted the drift rate at $1000{ }^{\circ} \mathrm{C}$ as a function of time the probe spent at $1000^{\circ} \mathrm{C}$. Note that the drift rate at $1000{ }^{\circ} \mathrm{C}$ was calculated as described in Section 3.3. We notice that after $100 \mathrm{~h}$ the drift rate drops below $+0.5 \mathrm{pm} \cdot \mathrm{h}^{-1}$ and this value continues to decrease with annealing time at a somewhat slower pace after the $100 \mathrm{~h}$ mark. Interestingly, after $300 \mathrm{~h}$ at $1000{ }^{\circ} \mathrm{C}$ for probe 28 we registered a negative drift rate of $-0.18 \mathrm{pm} \cdot \mathrm{h}^{-1}$ (blue shift). This pattern in the wavelength dynamics - the initial faster red shift followed by the slower blue shift-is common among various types of high-temperature FBGs [13] and strongly suggests that the underlying cause of the wavelength drifts is related to the fiber itself: residual stresses in the fiber, dopant diffusion, structural changes or a combination of these causes. Experiments are under way to see whether this negative trend continues and is reproducible.

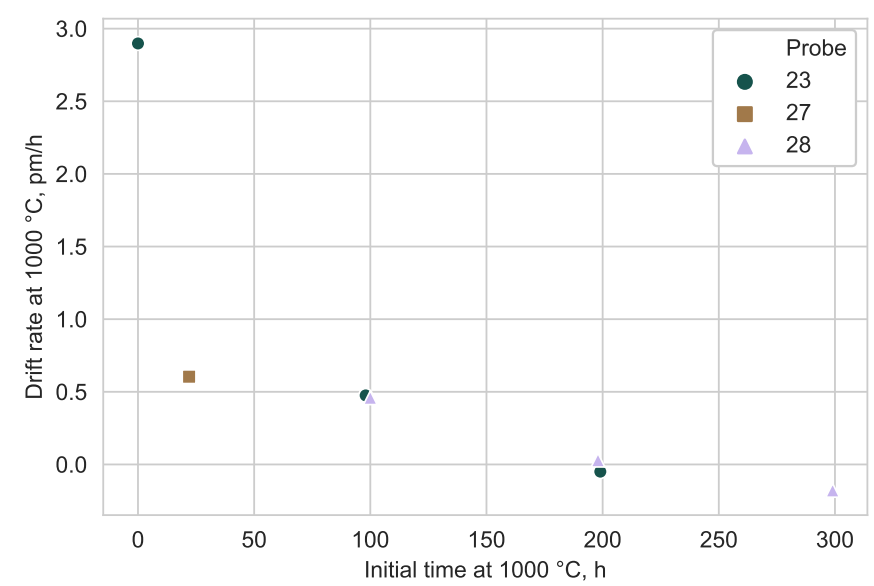

Figure 9. Drift rate at $1000{ }^{\circ} \mathrm{C}$ for probes 23,27 and 28 calculated by comparing the wavelength at $600{ }^{\circ} \mathrm{C}$ before and after annealing at $1000{ }^{\circ} \mathrm{C}$ (see the text for detailed explanations).

In Figure 10, we show what happens with the drift rate at a lower temperature $\left(600^{\circ} \mathrm{C}\right)$ as the probes 23,27 and 28 are repeatedly annealed at a higher temperature $\left(1000^{\circ} \mathrm{C}\right)$ for a time period indicated on the $\mathrm{X}$-axis. In general, we see that the drift rate of all the probes at $600{ }^{\circ} \mathrm{C}$ decreases as the annealing time at $1000{ }^{\circ} \mathrm{C}$ increases, although at a different pace for each probe. The lowest value of the wavelength drift we obtained was $+0.014 \mathrm{pm} \cdot \mathrm{h}^{-1}$ at $600{ }^{\circ} \mathrm{C}$ (corresponding to $+0.001{ }^{\circ} \mathrm{C} \cdot \mathrm{h}^{-1}$ ) after annealing for $400 \mathrm{~h}$ at $1000{ }^{\circ} \mathrm{C}$, the longest annealing time we have tried. Probe 23 was the only probe measured at $600{ }^{\circ} \mathrm{C}$ in pristine state (i.e., no pre-annealing at $1000{ }^{\circ} \mathrm{C}$ ) and its stability actually decreased after the first $100 \mathrm{~h}$ at $1000{ }^{\circ} \mathrm{C}$ before returning to the initial pre-annealing value after additional $100 \mathrm{~h}$ at $1000{ }^{\circ} \mathrm{C}$ - a possible indication that a drift rate above the asymptotic value recorded for probes 27 and 28 could be a result of the initial changes that happened at $1000{ }^{\circ} \mathrm{C}$ and are slowly relaxing with prolonged annealing. Several values are shown for probe 27 at the $22 \mathrm{~h}$ mark-since the probe was measured at different temperatures between two annealing 
cycles at $1000^{\circ} \mathrm{C}$ - and at the $122 \mathrm{~h}$ mark—when we completed two measurements to check the repeatability. In both cases, the repeatability of wavelength drift rate was measured to be $0.01 \mathrm{pm} \cdot \mathrm{h}^{-1}$ (one standard deviation), with the measurement on October 25 being the only exception, which bolsters our confidence in the trends we observed elsewhere.

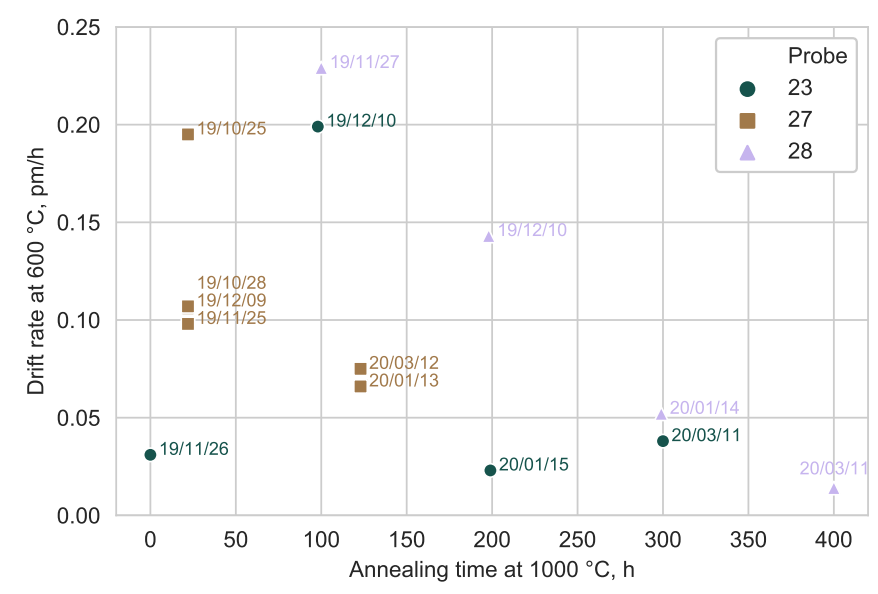

Figure 10. Drift rate at $600{ }^{\circ} \mathrm{C}$ for probes 23,27 and 28 measured in a Cs-PCHP. The date when the measurement was taken is also shown.

\section{Discussion}

To the best of our knowledge, the experimental results presented above are the most precise and the most accurate measurements of wavelength drifts available in the literature on high-temperature FBGs. These results could be interpreted along two somewhat separate lines. First, the experimental findings outlined in the previous section could be used as a guideline for future experiments that will study the wavelength drifts in hightemperature FBGs. Second, our experimental results put a lower limit on the wavelength drifts in the $400^{\circ} \mathrm{C}-1000^{\circ} \mathrm{C}$ temperature region which could be currently achieved with the high-temperature FBGs.

The summary of the factors to consider when measuring the wavelength drifts in $\pi$-phase-shifted FBGs (and to a large extent any high-temperature FBG) is as follows:

- Packaging of the FBG temperature sensor can significantly alter its performance (Section 3.1). Thus, the influence of packaging should be verified prior to starting long-term measurements and all the pertinent details of the packaging should be considered.

- $\quad$ FBGs produced under identical conditions can nevertheless differ significantly in their performance under identical conditions (Section 3.2). One should thus verify that the FBGs are interchangeable prior to subjecting them to different temperatures or perform individual calibrations over the entire temperature range of interest.

- FBGs wavelength drifts are not linear in time and can change abruptly in the course of measurements (Sections 3.3). Thus, linear drift rates should be interpreted with caution and longer experiments are required to obtain consistent drift rates.

- A corollary to the previous statement: wavelength measurement equipment and temperature equipment should maintain comparable stability at the time scale of the experiment.

- The birefringent nature of $\pi$-phase-shifted FBGs can contribute to increased measurement noise (Section 3.4), and one should make sure that the fibers are not disturbed during the measurements, both in terms of stress and in terms of ambient temperature.

- Previous thermal history can significantly influence the behaviour of doped silica fiber, and glass in general, at any given temperature (Sections 3.5 and 3.6). In this respect, a great care should be taken when comparing two different gratings and the details of the thermal treatment should be thoroughly documented. 
Following these guidelines will be especially important when very small wavelength drifts of the order of $0.01 \mathrm{pm} \cdot \mathrm{h}^{-1}$ are measured as in our experiments at $400{ }^{\circ} \mathrm{C}$ and at $600{ }^{\circ} \mathrm{C}$ after the prolonged annealing at $1000{ }^{\circ} \mathrm{C}$ (see Table 1 ).

These drift rates, even though small, still require further consideration in the metrology lab setting, where one is usually concerned with temperature changes of the order of $1 \times 10^{-4}{ }^{\circ} \mathrm{C}$ (or less), or during long-term temperature monitoring. The importance of the latter can be seen by converting the accumulated drift of the Bragg wavelength, for instance, over the span of 1 month at $600{ }^{\circ} \mathrm{C}$ into a fictitious short-term temperature variation (i.e., an error in temperature measurements) of $1{ }^{\circ} \mathrm{C}$ using the average sensitivity of $15 \mathrm{pm} \cdot{ }^{\circ} \mathrm{C}^{-1}$ for our packaged gratings at that temperature. Work is underway to see whether we can reduce the drift rates reported in Figure 10 even further by extending the annealing time at $1000^{\circ} \mathrm{C}$. In particular, we are interested in reducing the drift rate below $0.002 \mathrm{pm} \cdot \mathrm{h}^{-1}$ at $600{ }^{\circ} \mathrm{C}$ which will correspond to a $0.1^{\circ} \mathrm{C}$ change in displayed temperature over a month period, at which point the sensor could be re-calibrated.

One of the reasons why the cause(s) for the wavelength drift in high-temperature FBGs have not been uniquely identified yet is the absence of wide interest to the topic in the temperature metrology community and the lack of a shared careful approach to the measurement as we tried to argue in this paper. However, most importantly, the complex behaviour of the silica fiber at high temperatures (and any material for that matter) may be to blame. It has long been known [28], that glass' forming characteristics (viscosity, devitrification, phase separation), chemical durability (including dopant diffusion) and mechanical properties (residual stress, strength) are particularly important in dealing with fibers because of their small size and the resultant high surface area to volume ratio. Similarly to the bulk glass samples [26], these very same characteristics depend to a large extent on temperature and thermal history. Furthermore, the effective refractive index of the fiber core, which determines the Bragg wavelength, depends on all of these properties collectively! In addition, the single mode silica fiber, typically used for high-temperature work, is also a multi-phase system (fiber core plus cladding). Thus, the interplay between the temperature behaviour of the fiber core, the cladding and the boundary between the two (or more) layers becomes very important.

To add to the confusion, our own results on birefringence, described in Section 3.4, seem to challenge the assumption that the wavelength drift is caused by stress relaxation in the fiber. Furthermore, the presence of detectable wavelength drifts at the temperatures as low as $400{ }^{\circ} \mathrm{C}$ (see Table 1 and Figure 7) rules out the devitrification of glass as an explanation. As for the remaining explanation, the diffusion of Ge-dopant from the core will result in the reduction of the core's effective refractive index and thus will lead the blue wavelength drift, which is contrary to our observations. Perhaps, our planned experiments with the controlled gas atmosphere as described in Section 3.1 will shed more light on the cause(s) of the wavelength drift in high-temperature FBGs.

Finally, it is instructive to draw parallels between the silica fiber in FBGs and the platinum wire in high-temperature PRTs (a cautionary note: one should keep in mind that the stability issues with PRTs described above are currently several orders of magnitude smaller than with FBGs) [1] (pp. 153-198), [21] with a variant of the former sometimes predicted to eventually replace the latter [29]. Similar to high-temperature FBGs, each PRT is produced individually and carefully packaged. The specific details, such as the purity of platinum wire, the partial pressure of oxygen in the protective quartz sheath and the strain-free mounting of the wire coil inside the sheath, determine the unique response of the thermometer, define its long-term stability and contribute to the spread of measured temperatures in temperature fixed points [1] (pp. 153-198), [21]. In the same way as the interplay of dopant/impurity diffusion, devitrification/crystallization and residual stresses in silica fiber at high-temperatures is likely responsible for the wavelength drifts of FBGs (see Section 1), the diffusion and oxidation of impurities [30], re-crystallization of platinum and the stresses from mounting the wire on the quartz former [31] - all contribute to the stability of the PRT. Similarly to the $\pi$-phase-shifted FBGs studied in this work, PRTs are 
subjected to extensive annealing procedures at higher temperatures in order to eliminate drifts at lower temperatures, often with mixed results [32]. That said, if the wavelength drifts in FBGs cannot be eliminated or accounted for, then the sentiment from the excellent review on regenerated FBGs [33] might prove true: "from a pragmatic perspective, these experiments show that the basic optical fiber is not designed for high temperature operation, rather optimised for low temperature work...".

\title{
5. Conclusions
}

Despite the growing use of FBGs in high-temperature measurements in harsh environments, the important issue of their long-term stability in the range of $600{ }^{\circ} \mathrm{C}-1000{ }^{\circ} \mathrm{C}$ remains largely unaddressed. In this paper, we outlined some of the experimental caveats that could lead to inconsistent results and confusion in measuring wavelength drifts, such as: importance of FBG packaging; variability of FBGs even when they are produced under nominally identical conditions; non-linear nature of the Bragg wavelength drifts; long-term stability of the testing equipment; birefringence of FBGs; influence of the FBG's thermal history. Using the set of packaged $\pi$-phase-shifted FBGs for high wavelength resolution, pressure-controlled heat pipes for stable temperature environment and a tunable laser for stable wavelength measurements with a $0.1 \mathrm{pm}$ resolution we reported the most precise and accurate measurements of wavelength drifts available to date on high-temperature FBGs.

We also confirmed our previous observation: the wavelength stability of $\pi$-phaseshifted FBGs at lower temperature $\left(600^{\circ} \mathrm{C}\right)$ is significantly improved upon annealing at higher temperature $\left(1000^{\circ} \mathrm{C}\right)$. The lowest value of the wavelength drift we thus obtained was $0.02 \mathrm{pm} \cdot \mathrm{h}^{-1}$ at $600{ }^{\circ} \mathrm{C}$ after annealing the gratings for $200-400 \mathrm{~h}$ at $1000{ }^{\circ} \mathrm{C}$. The time duration required to achieve the aforementioned drift rate is FBG-specific, likely due to the nature of the FBG-inscription process.

It remains to be seen whether this drift rate could be further decreased and whether this conclusion applies universally to other types of high-temperature FBGs. The practical use of high-temperature FBGs in the temperature metrology lab or in long-term temperature monitoring depends on these future results.

Author Contributions: Conceptualization, S.D.; data curation, S.D., E.T., D.G. and C.H.; formal analysis, S.D.; funding acquisition, A.D.W.T. and S.J.M.; Investigation, S.D., E.T., D.G. and C.H.; methodology, S.D., D.G. and C.H.; project administration, A.D.W.T. and S.J.M.; resources, A.D.W.T. and S.J.M.; software, S.D.; supervision, S.D., A.D.W.T. and S.J.M.; validation, S.D.; visualization, S.D.; writing-original draft, S.D.; writing—review \& editing, S.D., D.G., C.H. and A.D.W.T. All authors have read and agreed to the published version of the manuscript.

Funding: This research received no external funding.

Informed Consent Statement: Not applicable.

Data Availability Statement: We do not have data publicly available.

Acknowledgments: S.D. would like to thank Michael Bakaic (Fibos) and Jakub Brelski (Fibos) for the technical support. S.D. would like to thank their colleagues Andrea Peruzzi and Patrick Rourke for valuable suggestions on how to improve the manuscript. S.D. would like to thank their wife Michelle Dedyulin for proofreading the manuscript.

Conflicts of Interest: The authors declare no conflict of interest.

\author{
Abbreviations \\ FBG fiber Bragg grating \\ PCHP pressure-controlled heat pipe \\ PRT platinum resistance thermometer \\ TPW triple point of water
}

The following abbreviations are used in this manuscript: 


\section{References}

1. Nicholas, J.V.; White, D.R. Traceable Temperatures, 1st ed.; Wiley: Toronto, ON, Canada, 1994; pp. 153-198, $239-281$.

2. Consultative Committee for Thermometry under the auspices of the International Committee for Weights and Measures. Techniques for Approximating the International Temperature Scale of 1990; BIPM: Paris, France, 1997; pp. 147-159.

3. Bao, Y.; Huang, Y.; Hoehler, M.S.; Chen, G. Review of fiber optic sensors for structural fire engineering. Sensors 2019, $19,877$. [CrossRef] [PubMed]

4. Wosniok, A.; Skoczowsky, D.; Schukar, M. Fiber optic sensors for high-temperature measurements on composite tanks in fire. J. Civ. Struct. Health Monit. 2019, 9, 361-368. [CrossRef]

5. Lindner, M.; Tunc, E.; Weraneck, K.; Heilmeier, F.; Volk, W.; Jakobi, M.; Koch, A.W.; Roths, J. Regenerated Bragg grating sensor array for temperature measurements during an aluminum casting process. IEEE Sens. J. 2018, 18, 5352-5360. [CrossRef]

6. Dutz, F.J.; Heinrich, A.; Bank, R.; Koch, A.W.; Roths, J. Fiber-optic multipoint sensor system with low drift for the long-term monitoring of high-temperature distributions in chemical reactors. Sensors 2019, 19, 5476. [CrossRef] [PubMed]

7. Laffont, G.; Cotillard, R.; Ferdinand, P.; Rodriguez, G.; Blevin, G. Regenerated fiber Bragg grating sensors for high temperature monitoring in sodium-cooled fast reactor. In Proceedings of the International Conference on Fast Reactors and Related Fuel Cycles, FR13, Paris, France, 4-7 March 2013.

8. Corre, Y.; Laffont, G.; Pocheau, C.; Cotillard, R.; Gaspar, J.; Roussel, N.; Firdaouss, M.; Gardarein, J.L.; Guilhem, D.; Missirlian, M. Integration of fiber Bragg grating temperature sensors in plasma facing components of the WEST tokamak. Rev. Sci. Instrum. 2018, 89, 063508. [CrossRef] [PubMed]

9. Dutz, F.J.; Boje, S.; Orth, U.; Koch, A.W.; Roths, J. High-temperature profile monitoring in gas turbine exhaust-gas diffusors with Six-Point fiber-optic sensor array. Int. J. Turbomach. Propuls. Power 2020, 5, 25. [CrossRef]

10. Walker, R.B.; Ding, H.; Coulas, D.; Grobnic, D.; Mihailov, S.J.; Duschesne, M.A.; Hughes, R.W.; McCalden, D.J.; Burchat, R.; Yandon R. High temperature monitoring of an oxy-fuel fluidized bed combustor using femtosecond infrared laser written fiber Bragg gratings. In Photonic Instrumentation Engineering III, Proceedings of the SPIE OPTO, San Francisco, CA, USA, 13-18 February 2016; Soskind, Y. G., Olson, C., Eds.; SPIE: Bellingham, WA, USA; Volume 9754, pp. 180-187.

11. Othonos, A. Bragg gratings in optical fibers: fundamentals and applications. In Optical Fiber Sensor Technology; Grattan, K.T.V., Meggitt, B.T., Eds.; Kluwer Academic Publishers: Boston, MA, USA, 2000; pp. 79-187.

12. Mihailov, S.J. Ultrafast laser inscribed fiber Bragg gratings for sensing applications. In Fiber Optic Sensors and Applications XIII, Proceedings of the SPIE Commercial + Scientific Sensing and Imaging, Baltimore, MA, USA, 17-21 April 2016; Eric Udd, E., Pickrell, G., Du, H.H., Eds.; SPIE: Bellingham, WA, USA, 2016; Volume 9852, pp. 173-192.

13. Grobnic, D.; Hnatovsky, C.; Dedyulin, S.; Walker, R.B.; Ding1, H.; Mihailov, S.J. Fiber Bragg grating wavelength drift in long term high temperature annealing. Sensors 2021, 21, 1454. [CrossRef] [PubMed]

14. Hnatovsky, C.; Grobnic, D.; Mihailov, S.J. High-temperature stable $\pi$-phase-shifted fiber Bragg gratings inscribed using infrared femtosecond pulses and a phase mask. Opt. Express 2018, 26, 23550-23564. [CrossRef] [PubMed]

15. Smelser, C.W.; Mihailov, S.J.; Grobnic, D. Formation of type I-IR and type II-IR gratings with an ultrafast IR laser and a phase mask. Opt. Express 2005, 13, 5377-5386. [CrossRef] [PubMed]

16. Available online: https://www.fibos.ca (accessed on 7 April 2021).

17. Swann, W.C.; Gilbert, S.L. Accuracy limits for simple molecular absorption based wavelength references. In Proceedings of the Technical Digest: Symposium on Optical Fiber Measuments, Boulder, CO, USA, 28-30 September 2004; pp. 15-18.

18. Gilbert, S.L.; Swann, W.C. Acetylene ${ }^{12} \mathrm{C}_{2} \mathrm{H}_{2}$ absorption reference for $1510 \mathrm{~nm}$ to $1540 \mathrm{~nm}$ wavelength calibration-SRM 2517a. In National Institute of Standards and Technology (US) Special Publications 260-133; National Institute of Standards and Technology: Boulder, CO, USA, 2001; pp. 1-11.

19. Merlone, A.; Coppa, G.; Bassani, C.; Bonnier, G.; Bertiglia, F.; Dedyulin, S.; Favreau, J.-O.; Fernicola, V.; van Geel, J.; Georgin, E.; et al. Gas-controlled heat pipes in metrology: More than 30 years of technical and scientific progresses. Measurement 2020, 164, 108103. [CrossRef]

20. Faghri, A. Heat Pipe Science and Technology; Taylor \& Francis: Washington, DC, USA, 1995; pp. 1-60.

21. Consultative Committee for Thermometry under the auspices of the International Committee for Weights and Measures. Guide to the Realization of the ITS-90; Platinum Resistance Thermometry; BIPM: Paris, France, 2018; pp. 1-56.

22. Nishioka, G.M. Adsorption/desorption of water on glass fiber surfaces. J. Non-Cryst. Solids 1990, 120, 34-39. [CrossRef]

23. Brunet-Bruneau, A.; Fisson, S.; Vuye, G.; Rivory, J. Change of $\mathrm{TO}$ and $\mathrm{LO}$ mode frequency of evaporated $\mathrm{SiO}_{2}$ films during aging in air. J. Appl. Phys. 2000, 87, 7303-7309. [CrossRef]

24. Alvarez-Herrero, A.; Heredero, R.L.; Bernabeu, E.; Levy, D. Adsorption of water on porous Vicor glass studied by ellipsometry. App. Opt. 2001, 40, 527-532. [CrossRef] [PubMed]

25. Hnatovsky, C.; Grobnic, D.; Mihailov, S.J. Birefringent $\pi$-phase-shifted fiber Bragg gratings for sensing at $1000{ }^{\circ} \mathrm{C}$ fabricated using an infrared femtosecond laser and a phase mask. J. Lightwave Technol. 2018, 36, 5697-5703. [CrossRef]

26. McLellan, G.W.; Shand, E.B. (Eds.) Properties of glass. In Glass Engineering Handbook, 3rd ed.; McGraw-Hill Book Company: Toronto, ON, Canada, 1984; pp. 2.1-2.17.

27. Peters, C.G.; Cragoe, C.H. Measurements on the thermal dilatation of glass at high temperatures. Sci. Pap. Bureau Stand. 1920, 16, 449-487. [CrossRef] 
28. Bagley, B.J.; Kurkjian, C.R.; Mitchell, J.W.; Peterson, G.E.; Tynes, A.R. Material, properties and choices. In Optical Fiber Telecommunications; Miller, S.E.; Chynoweth, A.G., Eds.; Academic Press: New York, NY, USA, 1979; pp. 167-231.

29. Ahmed, Z.; Klimov, N.; Purdy, T.P.; Herman, T.; Douglass, K.; Fitzgerald, R. Kundagrami, R. Photonic thermometry: Upending 100 year-old paradigm in temperature metrology. In Silicon Photonics XIV, Proceedings of the SPIE OPTO, San Francisco, CA, USA, 2-7 February 2019; Reed, G.T., Knights, A.P., Eds.; SPIE: Bellingham, WA, USA; Volume 10923, pp. 56-63.

30. Berry, R.J. Effect of Pt oxidation on Pt resistance thermometry. Metrologia 1980, 16, 117-126. [CrossRef]

31. Tanaka, Y.; Widiatmo, J.V.; Harada, K.; Kobayashi, T.; Yamazawa, K. A challenge to improve high-temperature platinum resistance thermometer. Int. J. Thermophys. 2017, 38, 76. [CrossRef]

32. Widiatmo, K.; Harada, K.; Yamazawa, J.V. Characterization of high-temperature platinum resistance thermometers at silver point. Int. J. Thermophys. 2017, 38, 43. [CrossRef]

33. Canning, J. Regeneration, regenerated gratings and composite glass properties: The implications for high temperature micro and nano milling and optical sensing. Measurement 2016, 79, 236-249. [CrossRef] 